\title{
3 Research Square

\section{Outcomes of COVID-19 Patients Intubated After Failure of Non-Invasive Ventilation: A Multicenter Observational Study.}

\section{Annalisa Boscolo}

Azienda Ospedaliera di Padova

\section{Laura Pasin}

Azienda Ospedaliera di Padova

Nicolò Sella

University of Padua

Chiara Pretto

University of Padua

Martina Tocco

University of Padua

Enrico Tamburini

University of Padua

Paolo Rosi

Regione del Veneto

\section{Enrico Polati}

University of Verona

Katia Donadello

University of Verona

Leonardo Gottin

University of Verona

Andrea Vianello

University of Padua

Giovanni Landoni

San Raffaele Hospital

Paolo Navalesi ( $\square$ pnavalesi@gmail.com )

University of Padua

\section{Research Article}

Keywords: COVID-19, SARS-CoV-2, in-hospital mortality, non-invasive mechanical ventilation, NIV, NIV failure, intubation, ICU 
Posted Date: April 15th, 2021

DOl: https://doi.org/10.21203/rs.3.rs-400059/v1

License: (c) (i) This work is licensed under a Creative Commons Attribution 4.0 International License. Read Full License 


\section{Abstract}

\section{Introduction}

The efficacy of non-invasive ventilation (NIV) in acute respiratory failure secondary to SARS-CoV-2 infection remains controversial. Current literature mainly examined efficacy, safety and potential predictors of NIV failure provided out of the Intensive Care Unit (ICU). On the contrary, the outcomes of ICU patients, intubated after NIV failure, remain to be explored. The aims of the present study are: 1) investigating in-hospital mortality in coronavirus disease 2019 (COVID-19) ICU patients receiving endotracheal intubation after NIV failure and 2) assessing whether the length of NIV application affects patient survival.

\section{Methods}

This observational multicenter study included all consecutive COVID-19 adult patients, admitted into the twenty-five ICUs of the COVID-19 VENETO ICU network (February-April 2020), who underwent endotracheal intubation after NIV failure.

\section{Results}

Among the 704 patients admitted to ICU during the study period, 280 (40\%) presented the inclusion criteria and were enrolled. The median age was 69 [60-76] years; 219 patients (78\%) were male. Inhospital mortality was $43 \%$. Only the length of NIV application before ICU admission (OR $2.03(95 \% \mathrm{Cl}$ 1.06 - 4.98), $p=0.03$ ) and age (OR 1.18 (95\% $\mathrm{Cl} 1.04-1.33), \mathrm{p}<0.01)$ were identified as independent risk factors of in-hospital mortality; whilst the length of NIV after ICU admission did not affect patient outcome.

\section{Conclusions}

In-hospital mortality of ICU patients intubated after NIV failure was $43 \%$. Days on NIV before ICU admission and age were assessed to be potential risk factors of greater in-hospital mortality.

\section{Introduction}

The efficacy of non-invasive ventilation (NIV), including both Biphasic Positive Airway Pressure (BiPAP) and non-invasive Continuous Positive Airway Pressure (CPAP), in patients with acute respiratory failure (ARF) secondary to coronavirus disease 2019 (COVID-19) is still debated $(1,2)$.

On the one hand, some authors believe that NIV represents a questionable option and controlled mechanical ventilation should be established as soon as possible because of the risks of patient selfinflicted lung injury and delayed intubation (3). On the other hand, solid evidence in favor of early intubation in COVID-19 ARF is still lacking, as several investigations failed to reveal a significant difference in mortality according to the time of intubation $(4,5)$. 
Recent studies showed that a short NIV trial could be beneficial to treat COVID-19 mild-to-moderate hypoxemic ARF (6-14). These investigations, however, were focused on the efficacy, safety and predictors of NIV failure applied outside the ICU (15-23). Few studies reported the rate of NIV application in ICU, ranging from $11-50 \%$, but the outcomes of critically ill patients, intubated after NIV failure, remain to be explored (6-9).

Therefore, we designed this study aiming to investigate the incidence of in-hospital mortality in ICU patients receiving endotracheal intubation after NIV failure and to ascertain whether the length of NIV application before intubation may affect patient survival.

\section{Methods}

The protocol was approved by the Institutional Ethical Committee of each participating centre (Ref: 4853A020). The study was conducted in accordance to Helsinki declaration and national regulation on study involving humans. Informed consent was obtained for each patient in compliance to national regulation and the recommendations of the Institutional Ethical Committee of Padova University Hospital.

We screened the records of all adult patients with confirmed SARS-CoV-2 infection, admitted into the twenty-five ICUs belonging to the COVID-19 VENETO ICU network (12), between February 28 and April 28, 2020. We deemed eligible for analysis only patients who received endotracheal intubation after experiencing NIV (either CPAP or BiPAP) failure (12). Patients exclusively receiving conventional and/or high-flow oxygen therapy or NIV, intubated after high-flow oxygen therapy, experiencing invasive mechanical ventilation without previous non-invasive treatments, with incomplete records or defined 'do not intubate' were excluded. Details on NIV setting, hospital organization and criteria for intubation are described in the supplementary material (Additional file, Methods).

The diagnosis of COVID-19 was made according to the WHO interim guidance (http://www.who.int/docs/default-source/coronaviruse/clinical-management-of-novel-cov.pdf). Laboratory confirmation of SARS-CoV-2 was defined as a positive result of real-time reverse transcriptase-polymerase chain reaction assay of nasopharyngeal swabs.

The following variables were collected: i) demographic data (age, gender, body mass index (BMI), onset of symptoms); ii) medical history (chronic diseases and long-term therapies, Charlson comorbidity index unadjusted for age (24)); iii) laboratory findings at ICU admission (blood count with formula, coagulation tests, C-reactive protein (CRP), procalcitonin, coagulation tests) and in-hospital treatments (i.e, ongoing therapies, including antiviral drugs and corticosteroids); iv) sequential organ failure assessment (SOFA) score at ICU admission; $v$ ) respiratory parameters before endotracheal intubation, i.e., positive endexpiratory pressure (PEEP), inspiratory pressure support above PEEP, fraction of inspired oxygen $\left(\mathrm{FiO}_{2}\right)$, $\mathrm{pH}$, arterial partial pressure of oxygen $\left(\mathrm{PaO}_{2}\right), \mathrm{PaO}_{2} / \mathrm{FiO}_{2}$, arterial partial pressure of carbon dioxide $\left(\mathrm{PaCO}_{2}\right)$ and respiratory rate; vi) length of NIV application, either overall, before and after ICU admission 
admission; vii) the hospital location where NIV was applied, i.e., when NIV was applied exclusively in medical wards, respiratory high dependency units or emergency departments (ED), patients were included in the 'out-of-ICU' group. When NIV was applied exclusively after ICU admission patients were included in the 'in-ICU' group. When NIV was applied before and after ICU admission, patients were included in the 'out- and in-ICU' group; viii) complications occurred during the ICU stay (see full description listed in the additional file, Table 1); ix) ICU and hospital lengths of stay; $x$ ) hospital location before ICU admission (medical wards, respiratory high dependency units or ED); $x i$ ) hospital mortality. 
Table 1

Description of clinical characteristics and respiratory parameters based on in-hospital mortality.

\begin{tabular}{|c|c|c|c|c|c|}
\hline & $\begin{array}{l}\begin{array}{l}\text { Overall } \\
\text { population, }\end{array} \\
n=280\end{array}$ & $\begin{array}{l}\text { in-hospital } \\
\text { survivors } \\
n=160 \\
(57 \%)\end{array}$ & $\begin{array}{l}\text { in-hospital } \\
\text { non- } \\
\text { survivors } \\
n=120 \\
(43 \%)\end{array}$ & $\begin{array}{l}\text { OR of } \\
\text { in-hospital } \\
\text { mortality } \\
(95 \% \mathrm{Cl})\end{array}$ & $\begin{array}{l}p- \\
\text { value }\end{array}$ \\
\hline \multicolumn{6}{|l|}{ Clinical characteristics } \\
\hline Age (years) & $69[60-76]$ & $\begin{array}{l}65[57- \\
72]\end{array}$ & $\begin{array}{l}73[68- \\
78]\end{array}$ & $\begin{array}{l}0.98(0.93- \\
1.03)\end{array}$ & 0.50 \\
\hline Gender (male) & $219(78 \%)$ & $122(76 \%)$ & $97(81 \%)$ & $\begin{array}{l}1.31(0.73- \\
2.35)\end{array}$ & 0.36 \\
\hline $\mathrm{BMI}\left(\mathrm{kg} / \mathrm{m}^{2}\right)$ & 27 [24-30] & $\begin{array}{l}28[25- \\
31]\end{array}$ & $\begin{array}{l}27[25- \\
30]\end{array}$ & $\begin{array}{l}0.98(0.93- \\
1.03)\end{array}$ & 0.50 \\
\hline Charlson comorbidity index & $1[1-3]$ & $1[1-2]$ & $2[1-4]$ & $\begin{array}{l}1.22(1.09- \\
1.38)\end{array}$ & $\hat{0.01}$ \\
\hline SOFA score at ICU admission & $5[4-8]$ & $4[3-7]$ & $6[4-10]$ & $\begin{array}{l}1.21(1.11- \\
1.31)\end{array}$ & $\dot{0.01}$ \\
\hline Onset of symptoms (days) & $6[3-9]$ & $7[3-9]$ & $6[3-10]$ & $\begin{array}{l}1.01(0.96- \\
1.05)\end{array}$ & 0.83 \\
\hline $\begin{array}{l}\text { Hospitalization before ICU } \\
\text { admission (days) }\end{array}$ & $3[1-5]$ & $3[1-4]$ & $3[1-7]$ & $\begin{array}{l}1.02(0.99- \\
1.06)\end{array}$ & 0.20 \\
\hline \multicolumn{6}{|l|}{$\begin{array}{l}\text { Respiratory parameters before } \\
\text { IMV }\end{array}$} \\
\hline $\operatorname{PEEP}\left(\mathrm{cmH}_{2} \mathrm{O}\right)$ & $10[8-10]$ & $10[5-16]$ & $10[5-16]$ & $\begin{array}{l}1.09(0.93- \\
1.28)\end{array}$ & 0.30 \\
\hline $\mathrm{FiO}_{2}$ & $\begin{array}{l}0.80[0.60- \\
1.00]\end{array}$ & $\begin{array}{l}0.70[0.40- \\
1.00]\end{array}$ & $\begin{array}{l}0.80[0.21- \\
1.00]\end{array}$ & $\begin{array}{l}1.02(1.01- \\
1.04)\end{array}$ & $\begin{array}{l}<.01 \\
0.01\end{array}$ \\
\hline $\mathrm{PaO}_{2} / \mathrm{FiO}_{2}$ & $\begin{array}{l}107[77- \\
150]\end{array}$ & $\begin{array}{l}118[90- \\
175]\end{array}$ & $\begin{array}{l}91[73- \\
131]\end{array}$ & $\begin{array}{l}0.99(0.98- \\
0.99)\end{array}$ & $\dot{0} 01$ \\
\hline $\mathrm{PaCO}_{2}(\mathrm{mmHg})$ & 40 [35-50] & $\begin{array}{l}39[35- \\
47]\end{array}$ & $\begin{array}{l}43[38- \\
55]\end{array}$ & $\begin{array}{l}1.04(1.02- \\
1.10)^{-}\end{array}$ & <. 01 \\
\hline
\end{tabular}

Data are expressed as median and InterQuartile Range [IQR] or number (\%), Odds Ratios (OR) and 95\% Confidence Interval (Cl).

Abbreviations: BMI: body mass index; SOFA: sequential organ failure assessment; ICU: intensive care unit; PEEP: positive end-expiratory pressure; $\mathrm{PaO}_{2} / \mathrm{FiO}_{2}$ : ratio between partial pressure of arterial oxygen and fraction of inspired oxygen; $\mathrm{PaCO}_{2}$ : partial pressure of carbon dioxide; NIV: non-invasive ventilation; IMV: invasive mechanical ventilation. 


\begin{tabular}{|c|c|c|c|c|c|}
\hline & $\begin{array}{l}\text { Overall } \\
\text { population, } \\
n=280\end{array}$ & $\begin{array}{l}\text { in-hospital } \\
\text { survivors } \\
n=160 \\
(57 \%)\end{array}$ & $\begin{array}{l}\text { in-hospital } \\
\text { non- } \\
\text { survivors } \\
n=120 \\
(43 \%)\end{array}$ & $\begin{array}{l}\text { OR of } \\
\text { in-hospital } \\
\text { mortality } \\
(95 \% \mathrm{Cl})\end{array}$ & $\begin{array}{l}p- \\
\text { value }\end{array}$ \\
\hline Respiratory rate (breaths/min) & 20 [16-2780] & $\begin{array}{l}22[16- \\
25]\end{array}$ & $\begin{array}{l}20[16- \\
28]^{-}\end{array}$ & $\begin{array}{l}1.01(0.97- \\
1.05)\end{array}$ & 0.76 \\
\hline \multicolumn{6}{|l|}{ Length of NIV application } \\
\hline $\begin{array}{l}\text { Length of NIV before ICU } \\
\text { admission (days) }\end{array}$ & $1[1-3]$ & $1[1-2]$ & $2[1-4]$ & $1.10(1.00-$ & 0.03 \\
\hline $\begin{array}{l}\text { Length of NIV after ICU } \\
\text { admission (days) }\end{array}$ & $2[1-3]$ & $2[1-3]$ & $2[1-4]$ & $\begin{array}{l}1.18(1.02- \\
1.37)\end{array}$ & 0.48 \\
\hline Overall length of NIV (days) & $2[1-4]$ & $2[1-3]$ & $2[1-5]$ & $\begin{array}{l}1.05(0.92- \\
1.20)\end{array}$ & 0.06 \\
\hline \multicolumn{6}{|c|}{$\begin{array}{l}\text { Data are expressed as median and InterQuartile Range [IQR] or number (\%), Odds Ratios (OR) and } \\
95 \% \text { Confidence Interval (CI). }\end{array}$} \\
\hline \multicolumn{6}{|c|}{$\begin{array}{l}\text { Abbreviations: BMI: body mass index; SOFA: sequential organ failure assessment; ICU: intensive care } \\
\text { unit; } P E E P \text { : positive end-expiratory pressure; } \mathrm{PaO}_{2} / \mathrm{FiO}_{2}: \text { ratio between partial pressure of arterial } \\
\text { oxygen and fraction of inspired oxygen; } \mathrm{PaCO}_{2}: \text { partial pressure of carbon dioxide; NIV: non-invasive } \\
\text { ventilation; IMV: invasive mechanical ventilation. }\end{array}$} \\
\hline
\end{tabular}

For patients being readmitted or moved to a different hospital, only data from the first admission were considered. This study followed the 'Strengthening the Reporting of Observational Studies in Epidemiology (STROBE) statement guidelines for observational cohort studies' (25) (Additional files, Table 2). Each investigator had a personal username and password and entered data into a pre-designed online data acquisition system (www.covid19veneto.it). Patients' privacy was protected by assigning a de-identified patient code. Prior to data analysis, two independent investigators and a statistician screened the database for errors against standardized ranges and contacted local investigators with any queries. Validated or corrected data were then entered into the database for final analysis. 
Table 2

Multivariable logistic regression analysis on the association between length of NIV application and inhospital mortality.

\begin{tabular}{|c|c|c|}
\hline & $\begin{array}{l}\text { OR } \\
\text { of in-hospital mor } \\
(95 \% \mathrm{Cl})\end{array}$ & p-value* \\
\hline Age (years) & $1.18(1.04-1.33)$ & $<0.01$ \\
\hline Charlson comorbidity index & - & - \\
\hline SOFA score at ICU admission & - & - \\
\hline $\mathrm{PaO}_{2} / \mathrm{FiO}_{2}$ before IMV & - & - \\
\hline Length of NIV before ICU admission (days) & $2.30(1.06-4.98)$ & 0.03 \\
\hline Length of NIV after ICU admission (days) & - & - \\
\hline \multicolumn{3}{|c|}{ Data are expressed as Odds ratios (OR) and 95\% Confidence Interval (Cl). } \\
\hline \multicolumn{3}{|c|}{$\begin{array}{l}\text { *: Stepwise regression models, which combine forward and backward selection methods in an } \\
\text { iterative procedure (with a significance level of } 0.05 \text { both for entry and retention) to select predictors } \\
\text { in the final multivariable model. Independent variables used in the stepwise approach were selected } \\
\text { considering their clinical relevance. }\end{array}$} \\
\hline \multicolumn{3}{|c|}{$\begin{array}{l}\text { Abbreviations: SOFA: sequential organ failure assessment; ICU: intensive care unit; } \mathrm{PaO}_{2} / \mathrm{FiO}_{2} \text { : ratio } \\
\text { between partial pressure of arterial oxygen and fraction of inspired oxygen; } \mathrm{NIV} \text { : non-invasive } \\
\text { ventilation; IMV: invasive mechanical ventilation. }\end{array}$} \\
\hline
\end{tabular}

\section{Statistical analysis}

Statistical analysis was conducted using Stata 16 (Stata Statistical Software: Release 16.1 College Station, Texas USA: StataCorp) and R version 3.5.2.

Categorical data were presented as absolute numbers and percentages; for continuous data, normality was tested by Skewness and Kurtosis tests. Means and standard deviations were used when the variables were normally distributed, while medians and interquartile ranges were used in case of nonnormally distributed variables. No imputation for missing data was planned.

Univariate analysis was used to investigate any difference between in-hospital survivors vs. nonsurvivors, concerning clinical characteristics, respiratory parameters before endotracheal intubation and the length of NIV application, both overall, before and after ICU admission.

Then, the independent predictors of in-hospital mortality have been identified through a stepwise multivariable regression model. This approach combines forward and backward selection methods in an iterative procedure (with a significance level of 0.05 both for entry and retention) to select predictors in the final multivariable model (26). Independent variables used in the stepwise approach, and selected 
considering their clinical relevance, were age, Charlson comorbidity index, SOFA score at ICU admission, $\mathrm{PaO}_{2} / \mathrm{FiO}_{2}$, length of NIV application before and after ICU admission.

Data were expressed as odds ratio (OR) and 95\% confidence interval $(95 \% \mathrm{Cl})$.

Curves of cumulative incidence of in-hospital mortality were drawn to describe in-hospital mortality stratified by: i) patients' characteristics (age); ii) length of NIV application prior to intubation; iii) and hospital location initially providing NIV. The median age and median length of NIV application, prior to intubation, of non-survivors were used as cut-off values for stratifying patients in two groups, as previously done (16). Since discharge must be considered an 'informative' censoring (27), cumulative incidence was calculated using methods accounting for competing risks and conventionally reported at 60-days. The Gray's test was used to assess the difference between cumulative incidence functions. The observation period started at the day of endotracheal intubation. All statistical tests were 2-tailed, and statistical significance was defined as $p<0.05$.

\section{Results}

Data prospectively collected from a total of 704 consecutive patients with confirmed SARS-CoV-2 infection, admitted to one of the twenty-five ICUs belonging to COVID-19 VENETO ICU Network from February 28 to April 28, 2020 (12), were screened for inclusion criteria. Among them, 424 patients (60\%) were excluded, while 280 (40\%) were finally enrolled (Fig. 1).

Baseline demographic and clinical characteristics of the study population are presented in Table 1 or listed in the Additional files, Table 1.

One-hundred-twenty patients (43\%) died during the hospital stay. These patients showed an increased number of comorbidities (Charlson comorbidity index $2[1-4]$ vs $1[1-2], p<0.01$ ), greater SOFA score at ICU admission (6 [4-10] vs 4 [3-7], p < 0.01) and more deteriorated gas exchange prior to endotracheal intubation (Table 1).

With respect to the hospital location initially providing NIV, 142 patients (51\%) were exclusively treated 'out-of-ICU'. Among those, 76 (54\%) died before hospital discharge. A total of 82 patients (29\%) received NIV only after ICU admission and 21 (36\%) died. Finally, 56 patients (20\%) failed 'out-of and in-ICU' NIV and 23 of them (41\%) died. Worth mentioning, 147 (53\%) patients received NIV before ICU admission in medical wards, while $77(27 \%)$ in respiratory high dependency units, according to illness severity. Finally, $56(20 \%)$ patients were directly admitted to ICU.

At univariate analysis, Charlson comorbidity index, SOFA score at ICU admission, $\mathrm{FiO}_{2}, \mathrm{PaO}_{2} / \mathrm{FiO}_{2}, \mathrm{PaCO}_{2}$ and the length of NIV before ICU admission were significantly related to in-hospital mortality (Table 1). On the contrary, at the multivariable logistic regression model, only age and the length of NIV before ICU admission were confirmed as independent predictors of in-hospital mortality (Table 2). 
In the overall study population, patients older than 73 years (median age of non-survivors) showed an inhospital mortality of $62 \%(95 \% \mathrm{Cl} 0.51-0.71)$, as opposed to patients $\leq 73$ years $(32 \%, 95 \% \mathrm{Cl} 0.26-0.39)$ $(p<0.01)$ (Fig. 2). Additionally, in-hospital mortality was significantly increased in patients receiving NIV for more than 2 days (median length of NIV application of non-survivors), as compared to those treated for 2 days or less (63\% vs $41 \%$; $p<0.01)$ (Fig. 3 ).

Finally, in-hospital mortality was higher in patients exclusively treated with 'out-of-ICU' NIV, as opposed to those exclusively treated with 'in-ICU' NIV (cumulative incidence $51 \%$ vs $24 \%, p<0.01$ ) (Fig. 4) or treated with NIV both outside and inside the ICU (cumulative incidence $51 \%$ vs $41 \%, \mathrm{p}=0.04$ ) (Additional files, Fig. 1).

\section{Discussion}

This study, conducted during the first wave of COVID-19 pandemia, shows $43 \%$ in-hospital mortality among patients who underwent endotracheal intubation after NIV failure for SARS-CoV-2. Moreover, length of NIV application outside the ICU exceeding 48 hours and age above 73 years were associated with greater mortality.

To the best of our knowledge, this is the first study focusing on the outcome of COVID-19 ICU patients intubated after NIV failure. Noteworthy, patients intubated after NIV failure showed a mortality rate no different from 292 patients receiving intubation without a previous NIV trial ( $42 \%$ vs $43 \%, p=0.66)$ (Figure 1), which suggests that attempting NIV did not worsen outcome even in case of intubation after failure.

Several previous studies described COVID-19 patients who underwent NIV outside ICU, often including patients receiving NIV as "ceiling" treatment $(15,16,19,21-23,28)$. Only a minority of these studies, however, reported the incidence of mortality of patients who were intubated after NIV failure. In keeping with our findings, Vaschetto et al. reported an in-hospital mortality of $41.0 \%$, while Karagiannidis et al reported a 30 -day mortality of $49.6 \%(14,16)$. Lower mortality rates were reported by Aliberti et al and Franco et al (26.5\% and $26.7 \%$, respectively) $(20,23)$. However, these two studies do not provide any information about patients' clinical conditions at ICU admission, which makes any comparison with our results extremely problematic. The only relevant difference that can be noticed is the median age of the study population in the study by Aliberti et al (60 [51-72] years) (20), quite lower than ours (69 [60-76] years).

With respect to the length of NIV before tracheal intubation, our results are consistent with the findings of Vaschetto et al, describing a large population of COVID-19 patients treated with CPAP outside ICU (16). In that study, 60-day in-hospital mortality was significantly higher in patients undergoing CPAP for more than 3 days (cumulative incidence $51 \%, 95 \% \mathrm{Cl}, 0.39-0.61$ ) as compared to those receiving CPAP for 3 days or less $(35 \%, 95 \% \mathrm{Cl}, 0.25-0.44)(16)$. 
While previous investigations were focused on the outcome of NIV delivered out of ICU $(15,16,19,21$ $23,28)$, our study provides detailed information on the outcome of intubation after NIV failure. Worth remarking, our data do not allow drawing any conclusion on the benefits of the application of NIV outside the ICU, as we do not consider the multitude of patients successfully treated with NIV in settings other than ICU in Veneto region during the study period (12).

Our study presents some limitations. First of all, like many of the investigations on COVID-19, it is an observational study, thus it bears the limits of this study design. Second, in keeping with previous guidelines, we did not distinguish between patients treated with CPAP and $\operatorname{BiPAP}(1,29)$, nor between patients supported with helmet and face mask, nor between continuous and intermittent treatments. Third, NIV was mainly delivered through helmets, which made impossible measuring tidal volume (30) and predicting the risk of patient self-inflicted lung injury (31). Finally, it is worth remarking that the observed outcomes do not necessarily reflect those of patients treated outside a pandemic condition.

In conclusion, $43 \%$ of ICU patients receiving intubation after NIV failure died. Length of NIV before ICU admission and age were independent predictors of in-hospital mortality. Our findings suggest that prompt intubation is advisable in the case of lack of improvement after 2 days of NIV delivered outside ICU.

\section{Abbreviations}

SARS-CoV-2, severe acute respiratory syndrome coronavirus 2

NIV, non-invasive ventilation

ARF, acute respiratory failure COVID-19, coronavirus disease 2019 ICU, intensive care unit BiPAP, biphasic positive airway pressure CPAP, continuous positive airway pressure $\mathrm{PaO}_{2} / \mathrm{FiO}_{2}$, the ratio between arterial partial pressure of oxygen and inspired fraction of oxygen BMI, body mass index CRP, C-reactive protein SOFA, sequential organ failure assessment

$I M V$, invasive mechanical ventilation $\mathrm{PEEP}$, positive end-expiratory pressure $\mathrm{FiO}_{2}$, fraction of inspired oxygen $\mathrm{PaO}_{2}$, arterial partial pressure of oxygen $\mathrm{PaCO}_{2}$, arterial partial pressure of carbon dioxide

CVVH, continuous venous-venous hemofiltration

ED, emergency department

OR, odds ratio

$\mathrm{Cl}$, confidence interval

ETI, endotracheal intubation

\section{Declarations}




\section{Ethical approval}

This was a multicenter, observational study performed in twenty-five hospitals of Veneto Region, Northern Italy, listed on the Acknowledgements. All the participating centers obtained Ethics Committee approval for the present research project, initially approved by the Institutional Ethical Committee of Padova University hospital on the $21^{\text {st }}$ April, 2020 (Ref: 4853AO20). Local investigators were responsible for ensuring data integrity and validity. The study was conducted in accordance to Helsinki declaration and national regulation on study involving humans. Informed consent was obtained for each patient in compliance to national regulation and the recommendations of the Institutional Ethical Committee of Padova University Hospital.

\section{Consent for publication}

Informed consent was obtained for each patient in compliance to national regulation and the recommendations of the Institutional Ethical Committee of Padova University Hospital.

\section{Availability of data and materials}

The datasets used and analyzed during the current study are available from the corresponding author on reasonable request.

\section{Competing interests}

The authors declare that they have no competing interests.

\section{Funding}

This study was funded by a grant provided by the Regional Government, Veneto, Italy. The regional database was commissioned to the Contract Research Organization Aleph srl (Milan, Italy).

\section{Authors' contributions}

$A B, L P, N S$ designed and conceived the study, performed statistical analysis, drafted the manuscript; PR, $E P, K D, L G, P N$ conceived the study and participated in its design and coordination; CP, MT, ET acquired data, coordinated data collection, and helped to draft the manuscript; AV, GL participated to design the study and substantially revised the draft; the COVID-19 VENETO ICU Network contributed to collect and interpret and data. All authors read and approved the final manuscript.

\section{ACKNOWLEDGEMENTS}

The Authors are grateful to all ICU doctors, residents, and nurses whose efforts, devotion to patients and passion made this timely report. 
Members of COVID-19 VENETO ICU Network, that we would like to be searchable through their individual PubMed records, are listed below:

i) O.C. Istituto di Anestesia e Rianimazione, Padova (Ilaria Valeri, MD; Giulio Andreatta, MD; Leonardo Gandolfi, MD; Alessandra Gadaldi, MD; Nicolò Brumana, MD; Edoardo Forin, MD; Christelle Correale, MD; Davide Fregolent, MD; Pier Francesco Pirelli, MD; Davide Marchesin, MD; Matteo Perona, MD; Nicola Franchetti, MD; Michele Della Paolera, MD; Caterina Simoni, MD; Tatiana Falcioni, MD; Alessandra Tresin, MD; Chiara Schiavolin, MD; Aldo Schiavi, MD; Sonila Vathi, MD; Daria Sartori, MD; Alice Sorgato, MD; Elisa Pistollato, MD; Federico Linassi, MD; Gian Lorenzo Golino, MD; Laura Frigo, MD); ii) Azienda OspedalieraUniversità di Padova, Padova (PD) (Eugenio Serra, MD; Demetrio Pittarello, MD; Ivo Tiberio, MD; Ottavia Bond, MD; Elisa Michieletto, MD; Luisa Muraro, MD; Arianna Peralta, MD; Paolo Persona, MD; Enrico Petranzan, MD; Francesco Zarantonello, MD; Tommaso Pettenuzzo, MD; Alessandro Graziano, MD; Alessandro De Cassai, MD); iii) U.O.C. Anestesia e Rianimazione, Presidio Ospedaliero “San Martino”, Belluno (BL), AULSS 1 Dolomiti (Lorenzo Bernardi, MD; Roberto Pianon, MD); iv) U.O.C. Anestesia e Rianimazione, Ospedale di Vittorio Veneto, Vittorio Veneto (TV), AULSS 2 Marca Trevigiana (Flavio Badii, MD); iv) U.O.C. Anestesia e Rianimazione, Ospedale di Conegliano, Conegliano (TV), AULSS 2 Marca Trevigiana (Enrico Bosco, MD); v) U.O.C. Anestesia e Rianimazione, Ospedale di Montebelluna, Montebelluna (TV), AULSS 2 Marca Trevigiana (Moreno Agostini, MD); vi) U.O.C. Anestesia e Rianimazione, Ospedale di Oderzo, Oderzo (TV), AULSS 2 Marca Trevigiana (Paride Trevisiol, MD); vii) U.O.C. Anestesia e Rianimazione, Ospedale Ca' Foncello, Treviso, AULSS 2 Marca Trevigiana (Antonio Farnia, MD; Mario Peta, MD); viii) U.O.C. Anestesia, Rianimazione e Terapia Antalgica, Presidio Ospedaliero di Dolo, Dolo (VE), AULSS 3 Serenissima (Lorella Altafini, MD); ix) U.O.C. Anestesia, Rianimazione e Terapia Antalgica, Presidio Ospedaliero di Mirano, Mirano (VE) AULSS 3 Serenissima (Mauro Antonio Calò, MD); x) U.O.C. Anestesia e Rianimazione, Ospedale SS. Giovanni e Paolo, Venezia, AULSS 3 Serenissima (Marco Meggiolaro, MD); xi) U.O.C. Anestesia e Rianimazione, Ospedale dell'Angelo, Mestre (VE), AULSS 3 Serenissima (Francesco Lazzari, MD; Ivan Martinello, MD; Giorgio Fullin, MD; Francesco Papaccio, MD); xii) U.O.C. Anestesia e Rianimazione, Ospedali di San Donà di Piave e Jesolo, San Donà di Piave (VE), AULSS 4 Veneto Orientale (Fabio Toffoletto, MD); xiii) U.O.C. Anestesia e Rianimazione, Ospedale di Cittadella, Cittadella (PD), AULSS 6 Euganea (Alfeo Bonato, MD; Camilla Sgarabotto, MD); xiv) U.O.C. Anestesia e Rianimazione, Ospedali Riuniti Padova Sud, Monselice (PD), AULSS 6 Euganea (Fabio Baratto, MD; Francesco Montacciani, MD; Alessandra Parnigotto, MD); xv) U.O.C. Anestesia e Rianimazione, Ospedali di Rovigo e Trecenta, Rovigo, AULSS 5 Polesana (Giuseppe Gagliardi, MD; Ferraro Gioconda, MD); xvi) U.O.C. Anestesia e Rianimazione, Ospedale Alto Vicentino, Santorso (VI), AULSS 7 Pedemontana (Luigi Ongaro, MD); xvii) U.O.C. Anestesia e Rianimazione, Ospedale San Bassiano, Bassano del Grappa (VI), AULSS 7 Pedemontana (Marco Baiocchi, MD); xviii) U.O.C Anestesia e Rianimazione, Ospedale di Vicenza, Vicenza (VI), AULSS 8 Berica (Vinicio Danzi, MD; Silvia De Rosa, MD); xix) U.O. Anestesia e Rianimazione B, Azienda Ospedaliera Universitaria Integrata Verona, Verona (VR); $x x$ ) U.O. Anestesia e Rianimazione A, Azienda Ospedaliera Universitaria Integrata Verona, Verona (VR) (Paolo Zanatta, MD); xxi) U.O.C Anestesia e Rianimazione, Ospedale Mater Salutis di Legnago, Legnago (VR), AULSS 9 Scaligera (Ezio Sinigaglia, MD; Alessandra da Ros, MD); xxii) U.O.C 
Anestesia e Rianimazione, Ospedale Magalini di Villafranca, Legnago (VR), AULSS 9 Scaligera (Simonetta Marchiotto, MD; Silvia Bassanini, MD); xxiii) Dipartimento di Anestesia, Rianimazione e Terapia Antalgica, IRCCS Sacro Cuore-Don Calabria, Negrar (VR) (Massimo Zamperini, MD); xxiv) U.O.S. Terapia Intensiva, Dipartimento di Anestesia, Rianimazione e Terapia Antalgica, IRCCS Sacro Cuore-Don Calabria, Negrar (VR) (Ivan Daroui, MD); xxv) U.O. Terapia Intensiva, Ospedale P. Pederzoli - Casa di Cura Privata SpA, Peschiera sul Garda (VR) (Walter Mosaner, MD); $x x v$ ) IRCCS San Raffaele Scientific Institute, Milan (MI) (Rosalba Lembo, MSc).

\section{References}

1. Rochwerg, B. et al. Navalesi $P$ at el. Official ERS/ATS clinical practice guidelines: noninvasive ventilation for acute respiratory failure.Eur Respir J. 2017 Aug31;50(2):1602426.

2. Cruces, P. et al. A physiological approach to understand the role of respiratory effort in the progression of lung injury in SARS-CoV-2 infection. Crit Care. 24 (1), 494 (2020).

3. Gattinoni, L. et al. COVID-19 pneumonia: different respiratory treatments for different phenotypes? Intensive Care Med. 46 (6), 1099-1102 (2020).

4. Hernandez-Romieu, A. C. et al. Timing of Intubation and Mortality Among Critically III Coronavirus Disease 2019 Patients: A Single-Center Cohort Study. Crit Care Med. 48 (11), e1045-e1053 (2020).

5. Lee, Y. H. et al. Clinical Significance of Timing of Intubation in Critically III Patients with COVID-19: A Multi-Center Retrospective Study. J Clin Med. 9 (9), 2847 (2020).

6. Bhatraju, P. K. et al. Covid-19 in Critically III Patients in the Seattle Region - Case Series. N Engl J Med. 382 (21), 2012-2022 (2020).

7. Cummings, M. J. et al. Epidemiology, clinical course, and outcomes of critically ill adults with COVID19 in New York City: a prospective cohort study. Lancet. 395 (10239), 1763-1770 (2020).

8. Grasselli, G. et al. Baseline Characteristics and Outcomes of 1591 Patients Infected With SARS-CoV-2 Admitted to ICUs of the Lombardy Region, Italy. JAMA. 323 (16), 1574-1581 (2020).

9. Yang, X. et al. Clinical course and outcomes of critically ill patients with SARS-CoV-2 pneumonia in Wuhan, China: a single-centered, retrospective, observational study. Lancet Respir Med. 8 (5), 475481 (2020).

10. Alhazzani, W. et al. Surviving Sepsis Campaign: Guidelines on the Management of Critically III Adults with Coronavirus Disease 2019 (COVID-19). Crit Care Med. 48 (6), e440-69 (2020).

11. Radovanovic, D. et al. Helmet CPAP to Treat Acute Hypoxemic Respiratory Failure in Patients with COVID-19: A Management Strategy Proposal.Journal of Clinical Medicine. 2020;9(4).

12. Pasin, L. et al. Regional COVID-19 Network for Coordination of SARS-CoV-2 outbreak in Veneto, Italy. J Cardiothorac Vasc Anesth. 34 (9), 2341-2345 (2020).

13. Ferrando, C. et al. Clinical features, ventilatory management, and outcome of ARDS caused by COVID-19 are similar to other causes of ARDS. Intensive Care Med. 47 (1), 144-146 (2020). 
14. Karagiannidis, C. et al. Case characteristics, resource use, and outcomes of $10 \dagger^{\wedge} 021$ patients with COVID-19 admitted to 920 German hospitals: an observational study. Lancet Respir Med. 8 (9), 853862 (2020).

15. Avdeev, S. N. et al. Noninvasive ventilation for acute hypoxemic respiratory failure in patients with COVID-19. Am J Emerg Med. 39, 154-157 (2020).

16. Vaschetto, R. et al. Outcomes of COVID-19 patients treated with continuous positive airway pressure outside ICU. ERJ Open Research. https://doi.org/10.1183/23120541.00541-2020 (2021).

17. Sartini, C. et al. Respiratory Parameters in Patients With COVID-19 After Using Noninvasive Ventilation in the Prone Position Outside the Intensive Care Unit. JAMA. 323 (22), 2338-2340 (2020).

18. Paternoster, G. et al. Awake pronation with helmet continuous positive airway pressure for COVID-19 acute respiratory distress syndrome patients outside the ICU: A case series. Med Intensiva. S02105691 (20), 30273-30274 (2020).

19. Bellani, G. et al. Noninvasive Ventilatory Support of COVID-19 Patients Outside the Intensive Care Units (WARd-COVID). Ann Am Thorac Soc. https://doi.org/10.1513/AnnalsATS.202008-10800C (2021).

20. Aliberti, S. et al. Helmet CPAP treatment in patients with COVID-19 pneumonia: a multicentre cohort study.Eur Respir J. 2020;56(4).

21. De Vita, N. et al. Predictors of intubation in COVID-19 patients treated with out-of-ICU continuous positive airway pressure. Pulmonology. S2531-0437 (21), 00002-00007 (2021).

22. Ramirez, G. A. et al. Continuous positive airway pressure and pronation outside the intensive care unit in COVID 19 ARDS. Minerva Med. https://doi.org/10.23736/S0026-4806.20.06952-9 (2020).

23. Franco, C. et al. Feasibility and clinical impact of out-of-ICU non-invasive respiratory support in patients with COVID-19 related pneumonia. Eur Respir J. 56 (5), 2002130 (2020).

24. Song, S. E. et al. The Prognostic Value of the Charlson's Comorbidity Index in Patients with Prolonged Acute Mechanical Ventilation: A Single Center Experience. Tuberculosis and Respiratory Diseases. 79 (4), 289-294 (2016).

25. von Elm, E. et al. The Strengthening the Reporting of Observational Studies in Epidemiology (STROBE) statement: guidelines for reporting observational studies. PLoS Med. 4 (10), e296 (2007).

26. Panwar, R., Madotto, F., Laffey, J. G. \& van Haren, M. P. F. Compliance Phenotypes in Early Acute Respiratory Distress Syndrome before the COVID-19 Pandemic. Am J Respir Crit Care Med. 202 (9), 1244-1252 (2020).

27. Resche-Rigon, M., Azoulay, E. \& Chevret, S. Evaluating mortality in intensive care units: contribution of competing risks analyses. Crit Care. 10 (1), R5 (2006).

28. Oranger, M. et al. Continuous positive airway pressure to avoid intubation in SARS-CoV-2 pneumonia: a two-period retrospective case-control study.Eur Respir J. 2020;56(2).

29. Keenan, S. P. et al. Clinical practice guidelines for the use of noninvasive positive-pressure ventilation and noninvasive continuous positive airway pressure in the acute care setting. CMAJ. 183, E195- 
E214 (2011).

30. Cortegiani, A. et al. Tidal volume estimation during helmet noninvasive ventilation: an experimental feasibility study. Sci Rep. 9, 17324 (2019).

31. Carteaux, G. et al. Failure of Noninvasive Ventilation for De Novo Acute Hypoxemic Respiratory Failure: Role of Tidal Volume. Crit Care Med. 44, 282-290 (2016).

\section{Figures}

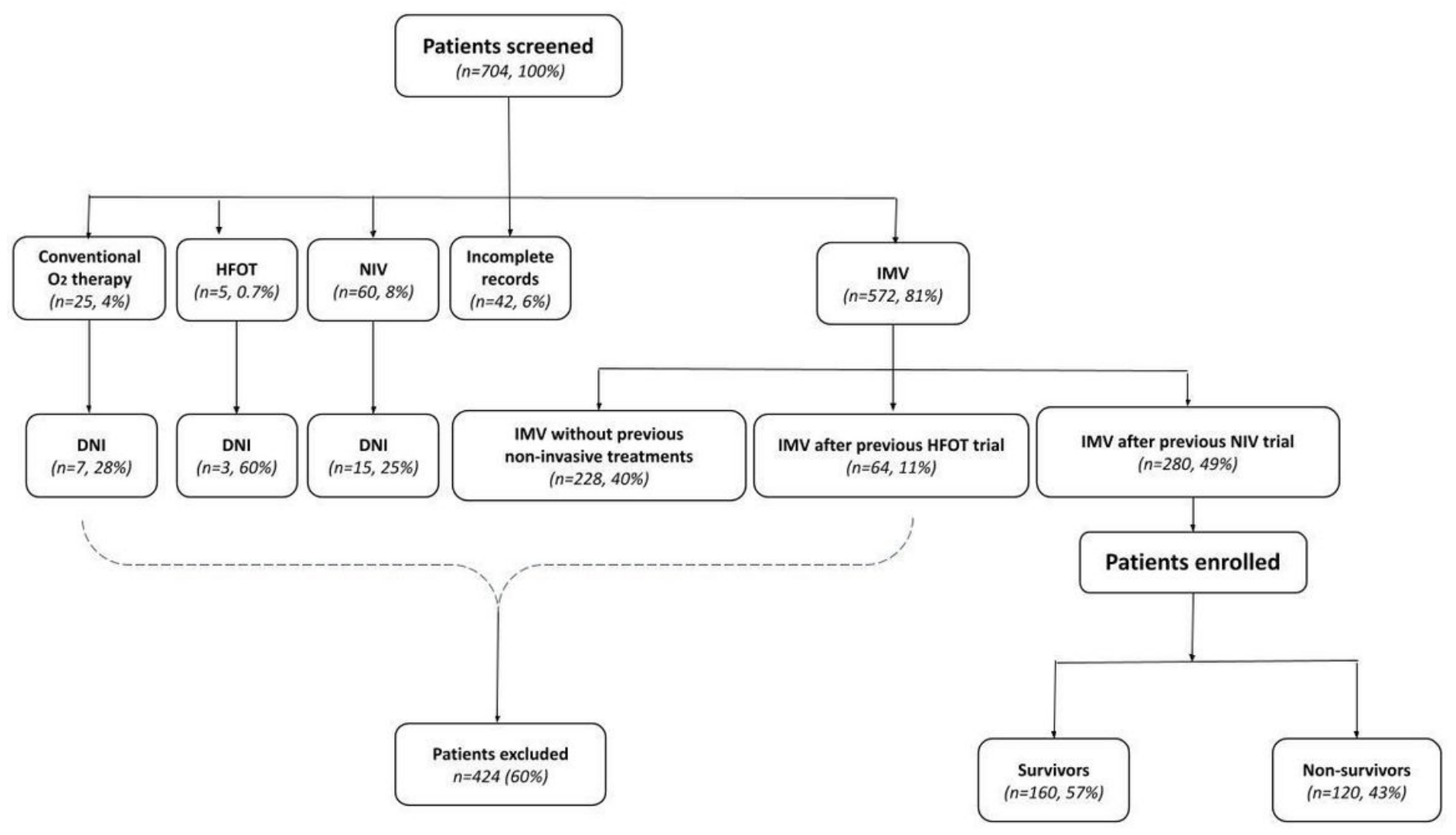

\section{Figure 1}

Flow chart of enrolled patients. Abbreviations: HFOT: high flow oxygen therapy; NIV: non-invasive ventilation; IMV: invasive mechanical ventilation; DNI: 'do not intubate'. 


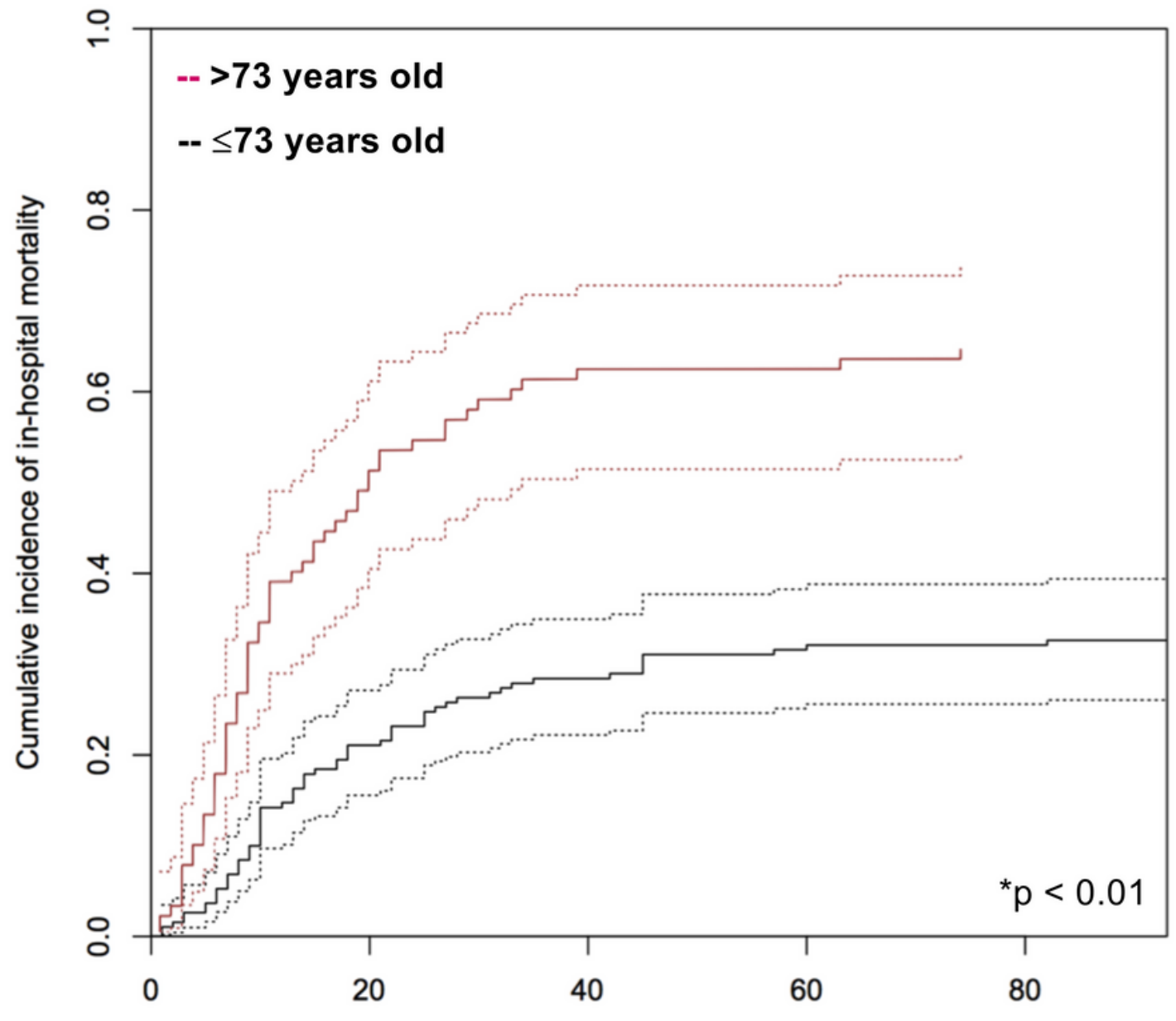

Time since ETI beginning

Numbers at risk

$\begin{array}{rrrrrr}-- & 90 & 39 & 14 & 4 & - \\ --- & 190 & 124 & 52 & 19 & 4\end{array}$

Cumulative incidence of in-hospital mortality at 60 days

$\begin{array}{ll}-- & 0.62(95 \% \mathrm{Cl} 0.51-0.71) \\ -- & 0.32(95 \% \mathrm{Cl} 0.26-0.39)\end{array}$

Figure 2

In-hospital mortality stratified by age ( $\leq$ or $>73$ years). P-value Gray's test was used for calculating equality of cumulative incidence function. The median age of non-survivors (=73 years) was considered as the cut-off value for stratifying patients in two groups. Abbreviations: NIV: non-invasive ventilation; ETI: endotracheal intubation. 


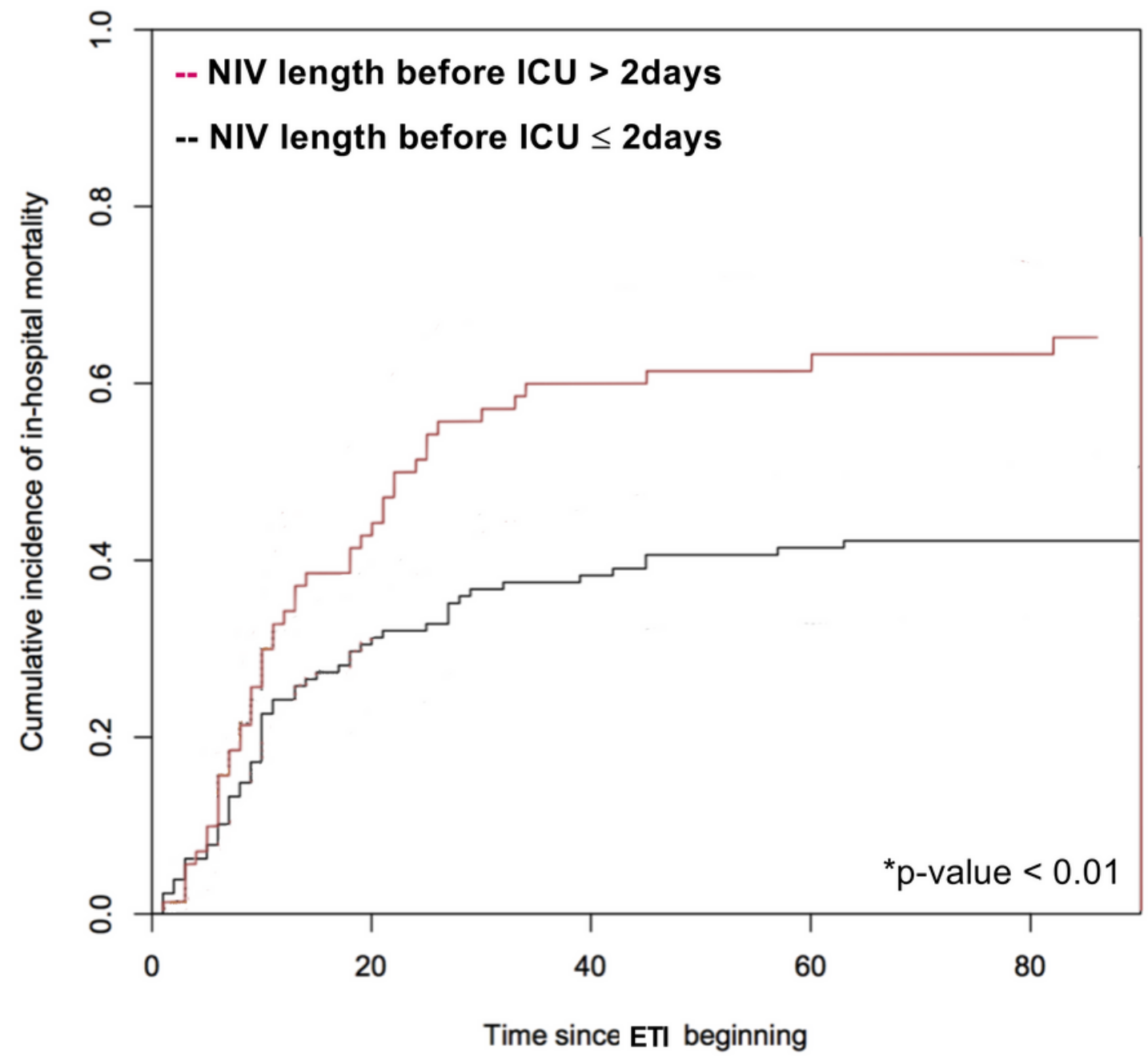

\section{Numbers at risk}

$\begin{array}{rrrrll}-- & 70 & 75 & 16 & 6 & 2 \\ -- & 128 & 37 & 33 & 11 & 2\end{array}$

Cumulative incidence of in-hospital mortality at 60 days
--- $\quad 0.63(95 \% \mathrm{Cl} 0.50-0.74)$
$--. \quad 0.41(95 \% \mathrm{Cl} 0.33-0.50)$

Figure 3

In-hospital mortality stratified by length of NIV application before ICU admission ( $\leq$ or $>2$ days). P-value Gray's test was used for calculating equality of cumulative incidence function. The median length of NIV application before ICU admission of non-survivors (=2 days) was considered as the cut-off value for stratifying patients in two groups. Abbreviations: NIV: non-invasive ventilation; ICU: intensive care unit; ETI: endotracheal intubation. 


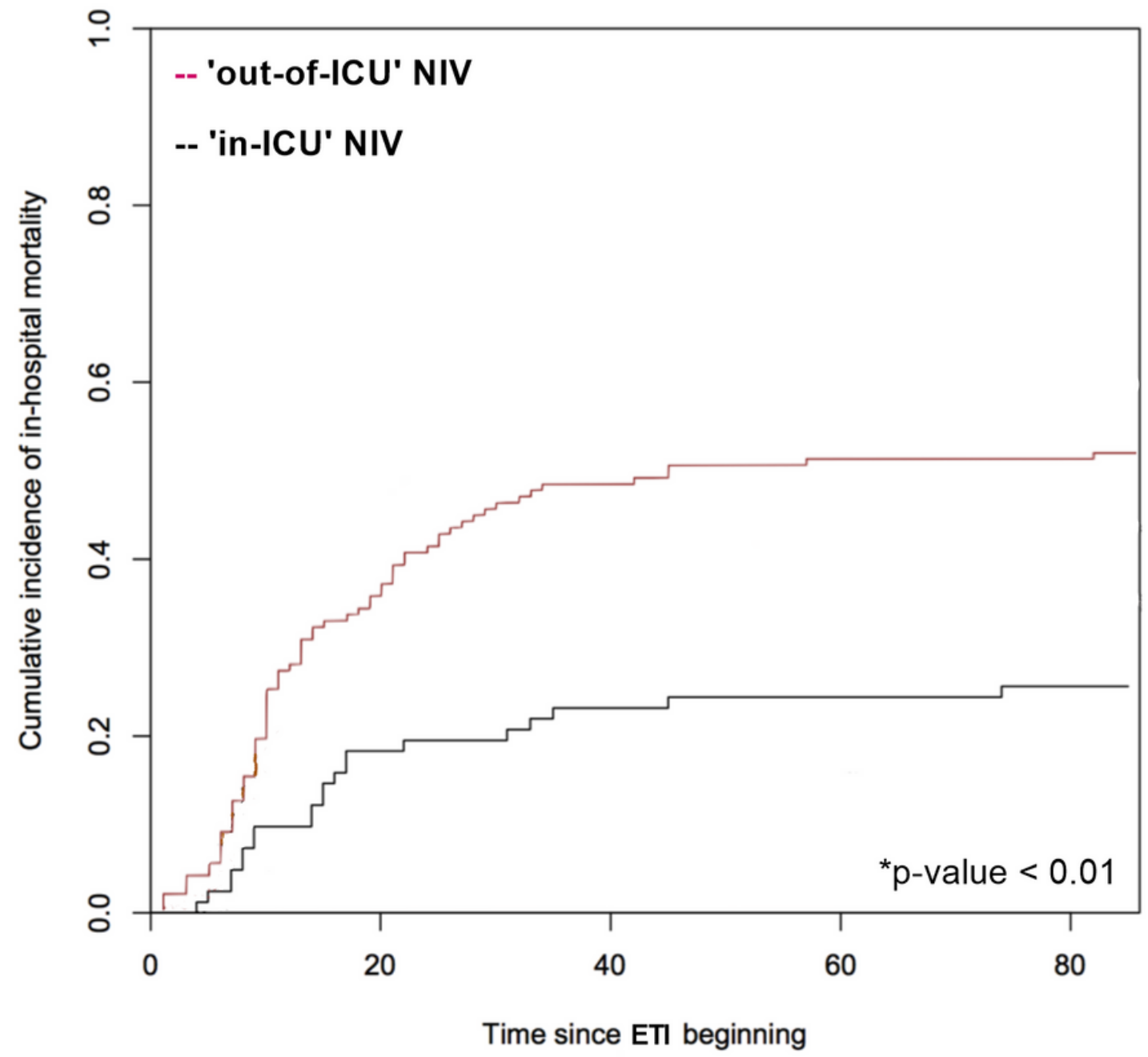

Numbers at risk

$\begin{array}{rrrrll}-- & 142 & 81 & 35 & 13 & 1 \\ -.- & 82 & 49 & 17 & 6 & 1\end{array}$

\section{Cumulative incidence of in-hospital mortality at 60 days}
$=0.51(95 \% \mathrm{Cl} 0.43-0.59)$
$-.-\quad 0.24(95 \% \mathrm{Cl} 0.16-0.34)$

\section{Figure 4}

In-hospital mortality stratified by hospital location. P-value Gray's test was used for calculating equality of cumulative incidence function. When NIV was applied exclusively in medical wards, respiratory high dependency units or Emergency Department, patients were included in the 'out-of-ICU' group. When NIV was applied exclusively after ICU admission patients were included in the 'in-ICU' group. Abbreviations: NIV: non-invasive ventilation; ICU: intensive care unit; ETI: endotracheal intubation. 


\section{Supplementary Files}

This is a list of supplementary files associated with this preprint. Click to download.

- Additionalfiles1.docx 